\title{
Estudio serológico de anticuerpos contra patógenos comunes, en gallinas de patio de la aldea El Caoba, Reserva de la Biosfera Maya, Guatemala
}

\author{
Héctor Aguilar-Miller \\ Investigador afiliado al Instituto de Investigación en Ciencia Animal y Ecosalud, \\ Facultad de Medicina Veterinaria y Zootecnia, Universidad de San Carlos de Guatemala \\ hectorjoseaguilarm@gmail.com \\ Dennis Guerra-Centeno \\ Director del Instituto de Investigación en Ciencia Animal y Ecosalud, \\ Facultad de Medicina Veterinaria y Zootecnia, Universidad de San Carlos de Guatemala \\ msc.dennisguerra@gmail.com \\ Carlos Valdez-Sandoval \\ Investigador en producción animal, Instituto de Investigación en Ciencia Animal y Ecosalud, \\ Facultad de Medicina Veterinaria y Zootecnia, Universidad de San Carlos de Guatemala \\ zoovaldez@gmail.com \\ Pilar Monterroso \\ Investigadora afiliada al Instituto de Investigación en Ciencia Animal y Ecosalud, \\ Facultad de Medicina Veterinaria y Zootecnia, Universidad de San Carlos de Guatemala \\ inesmvet@gmail.com \\ Rony García Anleu \\ Director del Departamento de Investigaciones Biológicas, Wildlife Conservation Society, Guatemala \\ rgarcia@wcs.org \\ Fecha de recepción: 03/02/2016 Fecha de aceptación: 26/05/2016
}

\section{Resumen}

Se realizó un estudio serológico en busca de anticuerpos contra agentes etiológicos comunes, en gallinas de patio (Gallus gallus) de la aldea El Caoba (AEC), situada en la zona de amortiguamiento de la Reserva de la Biosfera Maya, en Petén, Guatemala. Se tomaron aleatoriamente, muestras de sangre de 39 gallinas. Se buscaron anticuerpos contra el virus de influenza aviar tipo A (VIA), el virus de la enfermedad de Newcastle (VENC), el virus de la enfermedad de Gumboro (VEG), la bacteria Mycoplasma gallisepticum (MG) y la bacteria Salmonella pullorum (SP). El $46 \%$ de las gallinas estudiadas portaba anticuerpos contra el VIA; el $51 \%$ contra el VENC y el $95 \%$ contra el VEG. No se detectaron anticuerpos contra MG ni contra SP. Los anticuerpos contra el VENC se detectaron únicamente durante el muestreo del mes de septiembre. El 31\% de las gallinas muestreadas portaba, de manera concomitante, anticuerpos contra tres patógenos (VIA, VENC y VEG) y el 15\% contra dos patógenos (VENC y VEG). Se considera que la población dinámica de gallinas de patio de la AEC representa una potencial amenaza para la avicultura artesanal, la avicultura tecnificada, las aves silvestres y la población humana.

\section{Palabras clave}

Influenza aviar, enfermedad de Newcastle, enfermedad de Gumboro, Mycoplasma, Salmonella.

\begin{abstract}
A serological survey was performed to screen the presence of common avian pathogens in chickens (Gallus gallus) of El Caoba Community (ECC), a hamlet located inside the buffer zone of the Maya Biosphere Reserve in Petén, Guatemala. Thirty nine samples were processes for antibodies to type A H5N2 Avian Influenza Virus (AIV), Newcastle Disease Virus (NCDV), Infectious Bursitis Virus (IBV), Mycoplasma gallisepticum (MG) and Salmonella pullorum (SP). 46 percent of the sampled chickens carried antibodies against AIV; 51 percent against ND and 95 percent against EGV. No antibodies against SP or MG were detected. Antibodies against NDV were detected only during the sampling of September. Thirty one percent of the chickens carried, concomitantly, antibodies against three pathogens (AIV, NDV and IBV) and 15 percent against two pathogens (NDV and IBV). The dynamic population of backyard chickens in El Caoba was considered to be a potential threat to backyard poultry, farm poultry, wild bird diversity and human population.
\end{abstract}

\section{Keywords}

Avian Influenza, Newcastle Disease, Infectious Bursitis, Mycoplasma, Salmonella. 


\section{Introducción}

La gallina de patio constituye un recurso importante para las personas que viven en las áreas rurales de las zonas tropicales del mundo (Aini, 2013; Ajuyah, 2013; Kitalyi, 2013; Kumtakar y Kumtakar, 2013). En el ámbito de Guatemala -donde la pobreza alcanza al 53\% de la población-, es el recurso avícola más valioso (Mallia, 1999). Además de su valor de uso como alimento, esta especie tiene también un valor de cambio, funcionando como una mercancía que puede ser transada por otros bienes o servicios que el campesino necesita para satisfacer sus necesidades y para procurar su bienestar (Mallia, 1999; Moreki, 2010). En algunos lugares, este recurso es también utilizado en rituales religiosos o de sanación tales como "pasar el huevo" o "pasar la gallina" al enfermo (Ghidinelli, 1986; Moreki, 2010). En última instancia, la relevancia social de esta especie radica en el hecho de que es quizás la única fuente de alimento (carne y huevos) para las personas que viven en zonas remotas con suelos no arables (Guèye, 2002).

Dado que los campesinos ${ }^{1}$ no acostumbran realizar prácticas de manejo sanitario ni cuentan con asesoría profesional ni con apoyo gubernamental, la sobrevivencia de sus gallinas suele ser baja (Wilson et al., 1987). En la región septentrional de Guatemala, ocurre todos los años un síndrome que los comunitarios llaman "accidente" o "peste" -relacionado probablemente a enfermedades sobreagudas como las formas velogénicas de Newcastle o las variantes de alta patogenicidad de influenza aviarque causa gran mortalidad en las poblaciones de gallinas de patio, menguando o exterminando las aves y obligándolos a traer nuevos individuos para repoblar su parvada (M. Córdoba, comunicación personal, 26 de mayo de 2014).

1 Según el diccionario de la Real Academia Española, campesino se refiere a la persona que vive y trabaja habitualmente en el campo.
La gallina es una especie común en los paisajes de México y Guatemala desde principios del siglo XVI (De Sahagún, 1830; Gage, 2000). A pesar de eso, es muy poco lo que se ha publicado sobre las enfermedades de esta especie en condiciones de patio y sobre el impacto de estas en la economía del campesino. Desconocemos cuáles son los patógenos aviares que circulan en las poblaciones de gallinas de patio en la mayoría de comunidades rurales de Guatemala.

El hallazgo de patógenos aviares comunes en aves domésticas de comunidades cercanas a la Reserva de la Biosfera Maya (RBM), representaría no solo un riesgo de salud pública sino también una amenaza para la industria avícola y para la conservación de la diversidad de aves silvestres de Guatemala. La RBM contiene un alto porcentaje de las 724 especies de aves que se han registrado para Guatemala (Eisermann y Avendaño, 2006).

El entendimiento de la diversidad de patógenos en poblaciones de gallinas de patio de comunidades rurales sería el primer paso para diseñar intervenciones efectivas que permitan mejorar la sobrevivencia y productividad de las gallinas. Esto se traduciría en una disminución del riesgo de transmisión de enfermedades hacia humanos y hacia otras especies de aves, tanto domésticas como silvestres.

El objetivo en esta investigación exploratoria fue buscar evidencias de la presencia de patógenos comunes, en gallinas de patio de la $\mathrm{AEC}$, en la RMB. Los datos generados contribuyen a mejorar nuestro entendimiento sobre la diversidad de patógenos y sus relaciones epidemiológicas y ecosistémicas en el paisaje de Guatemala.

\section{Metodología}

\section{1 Área de estudio}

El estudio se desarrolló en la aldea El Caoba (AEC), ubicada en Flores, Petén, a una distancia de $35 \mathrm{~km}$ de la cabecera municipal, dentro de la Reserva de la Biosfera Maya. El Caoba, está 
situada entre las coordenadas 16 Q 215795.84 $\mathrm{m} \mathrm{E}, 1883233.42 \mathrm{~m} \mathrm{~N} ; 16$ Q $214877.66 \mathrm{~m}$ E $1884727.91 \mathrm{~m} \mathrm{~N}$, a una elevación de 354 msnm (Figura 1). La AEC, es una comunidad donde, según información proporcionada por el alcalde auxiliar, viven alrededor de 450 familias y la proporción de casas con gallinas es más o menos 60\% (Manuel Berganza, comunicación personal, 26 de mayo de 2014).

Figura 1

Localización de la aldea El Caoba y ubicación de puntos de muestreo
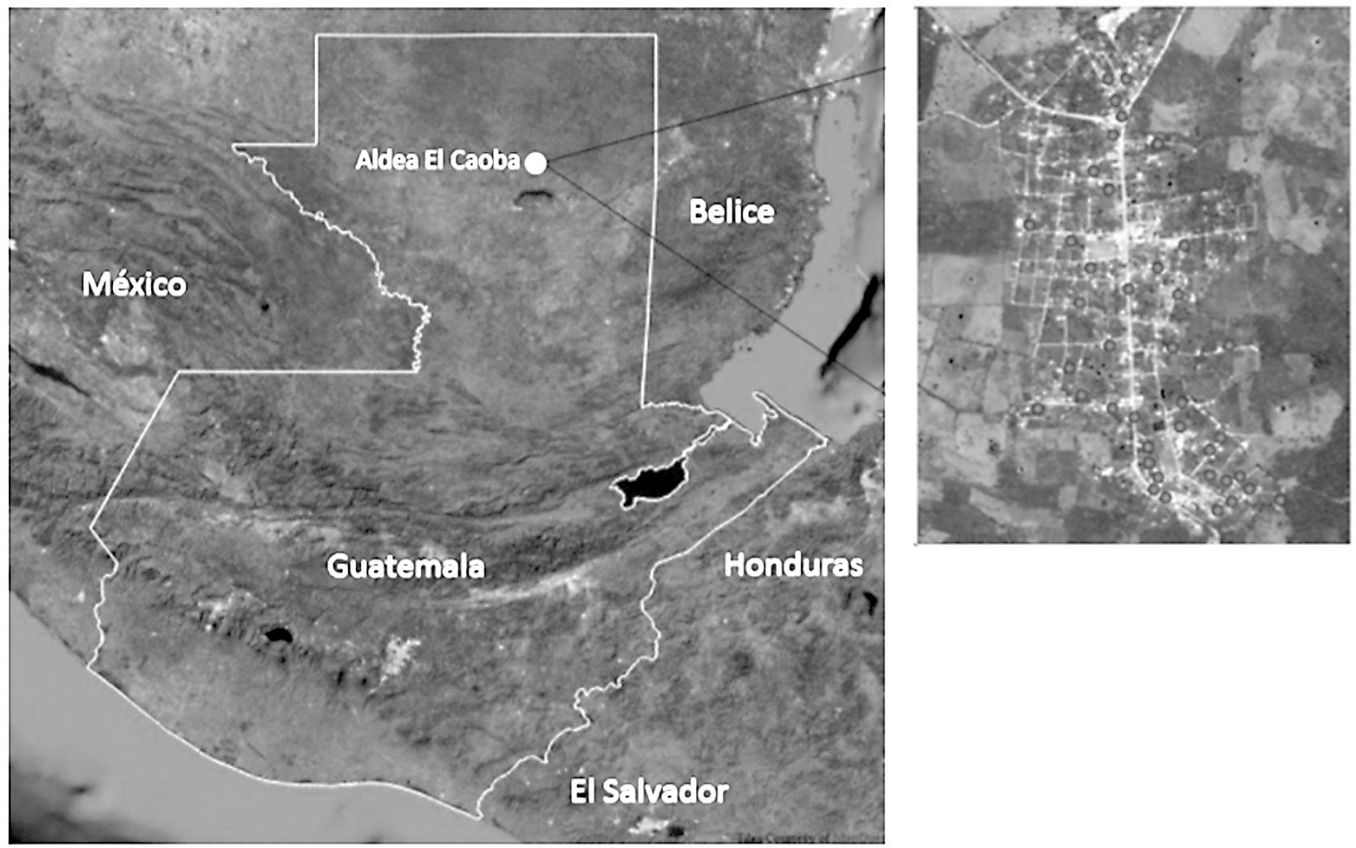

\subsection{Muestreo}

Considerando el carácter exploratorio del estudio, se utilizó un muestreo de tamizaje. A partir de la interpretación de una imagen de satélite de la aldea El Caoba, se numeraron las casas de la comunidad y se seleccionaron 40 aleatoriamente (Figura 1). Esta selección, corresponde al ocho por ciento de las 450 casas de la comunidad. Dada la cohesión que existe entre los individuos de una parvada y que el estudio tiene alcance exploratorio, se consideró suficiente muestrear un ave por parvada. Por conveniencia, el muestreo se dividió en dos esfuerzos: (1) el 29 de junio de 2014 y (2) el 22 de septiembre del mismo año. En cada esfuerzo de muestreo se tomaron muestras de 20 gallinas. Se incluyeron en el muestreo, gallinas jóvenes de entre
2 y 12 meses de edad. En el caso de las casas escogidas aleatoriamente donde no había gallinas, se seleccionó la casa siguiente, según el listado de números aleatorios.

\subsection{Toma y procesamiento de la muestra de sangre}

Se tomaron muestras de 3 mililitros de sangre venosa por punción de la vena radial. Inmediatamente, se colocaron las muestras en pajillas plásticas sin anticoagulante, se numeraron y se mantuvieron en refrigeración hasta su procesamiento en el Laboratorio de Referencia Regional de Sanidad Avícola (LARRSA), en el Campus de la Universidad de San Carlos de Guatemala. Una muestra se dañó en tránsito 
hacia la ciudad de Guatemala por lo que se procesaron 39 muestras.

\subsection{Determinación de anticuerpos circulantes}

Se examinaron muestras de suero para determinar la presencia de anticuerpos contra los siguientes agentes etiológicos aviares:

- $\quad$ Virus de Influenza aviar tipo A (VIA)

- Virus de la Enfermedad de Newcastle (VENC)

- Virus de la Enfermedad de Gumboro (VEG)

- $\quad$ Mycoplasma gallisepticum (MG)

- Salmonella pullorum (SP)

La presencia de anticuerpos en suero, se estableció usando las siguientes pruebas: Inhibición de la hemoaglutinación para el VIA y el VENC; ensayo por inmunoabsorción ligado a enzimas, de tipo directo para el VEG y prueba rápida en placa para MG y SP. Todas las pruebas serológicas se realizaron en el LARSSA.

Los anticuerpos contra el VIA (lgG, IgM) y contra el VENC (lgG, IgM) se establecieron mediante una prueba de inhibición de la hemoaglutinación, usando el procedimiento de referencia de la Oficina Internacional de Epizootias (OIE, 2015). Los anticuerpos contra el VEG (lgG, IgM) se determinaron mediante ensayo por inmunoabsorción ligado a enzimas, de tipo directo (BioChek®). Los anticuerpos contra MG y contra SP, fueron determinados mediante una prueba de aglutinación rápida en placa, usando el procedimiento de referencia de la Oficina Internacional de Epizootias (OIE, 2015). Todos los análisis fueron ejecutados en el LARRSA, en la Facultad de Medicina Veterinaria y Zootecnia de la Universidad de San Carlos de Guatemala. Los antígenos para las pruebas de detección de VIA (subtipo H5N2), VENC, MG y SP, fueron preparados en el LARRSA.

Los resultados de los títulos contra VIA, el VENC y el VEG fueron calculados como el valor recíproco de la dilución más alta que no causó hemoaglutinación; los del VEG, como los títulos ELISA de la prueba BioChek $®$ y los de MG y SP en escala nominal (positivo o negativo). El punto de corte para la interpretación de una muestra positiva para el VIA y el VENC fue la dilución 1:4 y para el VEG fue un valor de S/P de 0.2 o mayor.

Para el VIA, el VENC y el VEG, se calcularon los valores mínimo y máximo y la media geométrica del título de anticuerpos.

\section{Resultados}

Se detectaron anticuerpos contra varios patógenos aviares circulando en la población de gallinas de patio de la AEC. Algunas gallinas portaban, de manera concomitante, anticuerpos contra varios patógenos.

El $46 \%$ de las gallinas estudiadas portaba anticuerpos contra el VIA; el 51\% contra ENC y el 95\% contra EG. No se detectaron anticuerpos contra MG ni contra SP. Los anticuerpos contra VENC se detectaron únicamente durante el muestreo del mes de septiembre. El 31\% de las gallinas muestreadas, portaba anticuerpos contra tres patógenos (VIA, VENC y VEG) y el $15 \%$ contra dos patógenos (VENC y VEG). En el Cuadro 1 se muestra la frecuencia de casos de anticuerpos séricos contra los agentes etiológicos, en las gallinas muestreadas. 


\section{Cuadro 1}

Frecuencia de casos reactores a anticuerpos contra agentes etiológicos, en gallinas de la aldea El Caoba, Reserva de la Biosfera Maya, Flores, Petén, Guatemala.

\begin{tabular}{crr|}
\hline \multirow{2}{*}{ Agente etiológico } & \multicolumn{2}{c|}{ Frecuencia de casos } \\
\hline VIA & Positivos (\%) & Negativos (\%) \\
\hline VENC $^{2}$ & $18(46.1)$ & $21(53.9)$ \\
\hline VEG $^{3}$ & $20(51.3)$ & $19(48.7)$ \\
\hline MG $^{4}$ & $37(94.9)$ & $02(5.1)$ \\
\hline SP $^{5}$ & $0(0)$ & $39(100)$ \\
\hline
\end{tabular}

Nota: 'Virus de Influenza aviar tipo A (VIA), ${ }^{2}$ Virus de la Enfermedad de Newcastle, ${ }^{3}$ Virus de la Enfermedad de Gumboro, ${ }^{4}$ Mycoplasma gallisepticum, ${ }^{5}$ Salmonella pullorum.

Los valores mínimo y máximo y la media geométrica de los títulos de anticuerpos con- tra los agentes etiológicos estudiados, se muestran en el Cuadro 2.

\section{Cuadro 2}

Títulos de anticuerpos contra agentes etiológicos, en gallinas de la aldea El Caoba, Reserva de la Biosfera Maya, Flores, Petén, Guatemala.

\begin{tabular}{cccc}
$\begin{array}{c}\text { Agente } \\
\text { etiológico }\end{array}$ & $\begin{array}{c}\text { Valor } \\
\text { Mínimo }\end{array}$ & $\begin{array}{c}\text { Valor } \\
\text { Máximo }\end{array}$ & $\begin{array}{c}\text { Media } \\
\text { geométrica }\end{array}$ \\
\hline VIA* $^{*}$ & 4 & 64 & 18.89 \\
\hline VENC* $^{*}$ & 4 & 32 & 6.50 \\
\hline VEG $^{* *}$ & 305 & 11395 & 2965.00 \\
\hline
\end{tabular}

Nota: *Valores calculados a partir de los recíprocos de las diluciones. **Valores calculados a partir de los títulos de ELISA - BioChek.

\section{Discusión}

Antes de analizar los resultados, deben tomarse en cuenta algunas consideraciones. La primera, es de índole inmunológica, pues según información proporcionada por los comunitarios durante la fase de toma de muestras, en la AEC no se acostumbra vacunar a las gallinas de patio. Por lo tanto, la presencia de anticuerpos circulantes, debería interpretarse como el resultado de la interacción entre los patógenos de campo y el sistema inmune de las gallinas. De los anterior se deriva que la presencia de anticuerpos, es un indicio de la existencia de patógenos aviares en el ambiente (Wunderwald y Hoop, 2010).

La segunda consideración es de índole ecológica. En la AEC -y en muchas otras aldeas de Guatemala y de otros países-, las gallinas forrajean vagando libremente en los patios de las casas y duermen en grupos compactos dentro de un corral o en un árbol contiguo a la casa (Ajuyah, 2013; Mallia, 2013; Kitalyi, 2013; 
Ramlah, 2013). Esta cohesión que exhiben las parvadas de gallinas de patio, favorece el contagio y la diseminación de los organismos patógenos cuya dispersión es denso dependiente (Camacho-Escobar et al., 2006).

En esas condiciones, si una gallina entra en contacto con un patógeno de transmisión directa, las probabilidades de que todo el grupo lo haga, son altas, tanto por la exposición simultánea de la parvada a la fuente inicial del patógeno, como por la exposición de las aves de la parvada a las partículas eliminadas por los individuos que se enferman. En tal sentido, podemos considerar que el hallazgo de anticuerpos en un individuo de la parvada, refleja, en cierta medida, la exposición del grupo al patógeno que originó la producción de esos anticuerpos.

Además del contacto que se da entre los individuos de una parvada, también se produce cierto contacto entre las parvadas vecinas. Dado que los patios de las casas de las comunidades rurales en los países en vías de desarrollo no suelen estar cercados o separados por barreras físicas, hay un traslape en los territorios de forrajeo de las gallinas de patio (Camacho-Escobar et al., 2006). Este contacto de los grupos en las zonas de traslape podría favorecer la transmisión de patógenos de una parvada a otra dentro de una comunidad.

La detección de anticuerpos contra VIA, subtipo $\mathrm{H} 5 \mathrm{~N} 2$, de baja patogenicidad, en el $46 \%$ de las aves muestreadas es quizás el hallazgo más relevante de la presente investigación en términos de epidemiología y salud pública. Se sabe que en Guatemala, circulan varios subtipos de este virus (González-Reiche y Pérez, 2012; Senne, 2007). Una cepa H5N2 de virus de influenza aviar proveniente de México, se detectó en Guatemala en el año 2000 (Suarez et al., 2002). Además de esa cepa H5N2, detectada en aves de corral, también circulan en Guatemala las cepas H7N9, H11N2, H3N8, H5N3, H8N4 y H5N4, detectadas en patos silvestres de la especie Anas discors (González-Reiche et al., 2012). También se han detectado virus de cepas indeterminadas de influenza aviar en dos especies de aves: un pájaro carpintero Melanerpes aurifrons y en un mosquero Myarchus tyrannulus (González-Reiche et al., 2012). En la comunidad de Uaxactún, que está situada cerca de la AEC, no se detectaron anticuerpos contra el VIA en gallinas de patio (Mérida, et al., 2016) lo cual sugiere que la distribución espacial del virus podría ser focalizada.

Las variantes de VIA que circulan en Guatemala, no se limitan a nuestro territorio. La cepa H5N2 que se detectó localmente en el año 2000, se aisló posteriormente en Estados Unidos, en un loro frente roja (Amazona autumnalis) que provenía del comercio ilegal (Hawkins et al., 2006). Esta variante -que circula en Guatemala- fue transferida experimentalmente a pollos, patos y pavos y a pesar de que no causó signos clínicos, alcanzó altos títulos en estos hospederos (Pillai et al., 2007).

En el 2005, ocurrieron en Japón dos brotes de influenza aviar que resultaron en el sacrificio de 5.78 millones de pollos de 41 granjas (Okamatsu et al., 2007). En los pollos afectados, se aislaron 16 virus $\mathrm{H} 5 \mathrm{~N} 2$, todos derivados de la cepa H5N2 de virus de influenza aviar circulante en Guatemala, México y El Salvador (Okamatsu et al., 2007). Durante este brote también se detectaron anticuerpos en empleados de granjas avícolas de la prefectura de Ibaraki (Ogata et al., 2008). Esto pone de manifiesto la movilidad de los virus en un entorno globalizado.

Regresando al ámbito local, la circulación del VIA en gallinas de la AEC podría generar varios efectos. Por un lado, los virus de este tipo son mutagénicos y constituyen un riesgo potencial para la población humana. El Caoba se encuentra a menos de $30 \mathrm{~km}$ de las ciudades de Santa Elena, San Benito y Flores, que no sólo son ciudades densamente pobladas, sino que son sitios turísticos internacionales. Por 
otro lado, estos virus suelen comportarse de manera patógena o virulenta cuando afectan a un nuevo hospedero. Los subtipos $\mathrm{H} 5$ y $\mathrm{H} 7$ de virus de influenza aviar de baja patogenicidad han mutado a variedades altamente patogénicas para aves, principalmente cuando tienen oportunidad de infectar a gallináceas domésticas (Beldomenico y Uhart, 2008; Webster et al., 2007). El hecho que la comunidad de El Caoba se encuentre en la zona de amortiguamiento de la RBM, a tan solo nueve kilómetros del Parque Nacional Tikal y muy cerca de otras áreas protegidas, representa un riesgo de transmisión de patógenos aviares de las gallinas a las aves silvestres y esto podría tener implicaciones en la conservación de la diversidad biológica.

Algunas aves como el zanate (Quiscalus mexicanus), una especie invasiva cuya expansión se ve favorecida por la actividad antrópica ${ }^{2}$ (Christensen, 2000; MacGregor-Fors et al., 2009; Wehtje, 2003) y la paloma de alas blancas (Zenaida asiatica) que es una especie sinantrópica ${ }^{3}$ (Glass et al., 2002; Small et al., 2005), podrían actuar como vectores de VIA y otros patógenos aviares entre las poblaciones de gallinas de patio y la comunidad de especies de aves silvestres en el agropaisaje de las zonas de amortiguamiento y en la zona núcleo de la RBM.

Las aves acuáticas son reconocidas como los reservorios naturales de los VIA (Gaidet et al., 2008; Olsen et al., 2006). La migración que exhiben muchas aves acuáticas es de gran relevancia en la epidemiología de la influenza aviar (Vandergrift et al., 2011). En el caso de Guatemala, se ha identificado a la cerceta de ala azul (Anas discors) como la especie que mantiene y transporta el virus durante la migración desde Estados Unidos hasta Centro América y Sur América (González-Reiche et al., 2012; Ramey et al., 2014). Esta especie de pato, es la más

2 La actividad antrópica, es aquella relativa el ser humano.

3 Especie sinantrópica es aquella capaz de habitar en ecosistemas antrópicos. abundante en Guatemala (Sigüenza, 2007) y es una de las más distribuidas en los humedales de la RBM (Eisermann y Avendaño, 2006).

La enfermedad de Newcastle, es otra entidad cuyo hallazgo en la AEC preocupa, debido a que junto con la influenza aviar son las enfermedades más temidas a nivel mundial (Alexander, 1995, 2000). En Uaxactún, se reportó una prevalencia de $41 \%$, en muestras de gallinas de patio (Mérida et al., 2016). EI VENC proveniente de poblaciones de aves domésticas ha sido identificado como un riesgo biológico para especies de aves amenazadas de extinción con poblaciones pequeñas y aisladas (Gottdenker et al., 2005). Se cree que las 7,000 especies de aves existentes pueden ser afectadas por este patógeno que de hecho, se ha reportado en 250 de estas especies (Schelling et al., 1999). Se considera, sin embargo, que las acciones humanas dirigidas a las poblaciones de aves de corral, contribuyen más a la diseminación de la enfermedad de Newcastle, que los movimientos migratorios de las aves (Schelling et al., 1999).

El alto porcentaje de circulación de anticuerpos contra la enfermedad de Gumboro, encontrado en este estudio tiene también implicaciones ecológicas y económicas. Ecológicas, porque al tratarse de un virus de fácil transmisión, múltiples serotipos y poca habilidad de estimular una respuesta inmune cruzada en los hospederos (Cavanagh y Gelb, 2003), es capaz de afectar poblaciones enteras de aves, tanto domésticas como silvestres. Económicas, porque es una enfermedad que causa grandes pérdidas a la industria avícola, aun cuando se hayan instituido programas de vacunación (Cavanagh, 2007).

Otro aspecto relevante sobre el hallazgo de anticuerpos contra el VEG es el hecho de que esta enfermedad causa inmunosupresión (Sharma et al., 2000). Se sabe que el VEG afecta la habilidad de los pollos para responder a la enfermedad de Newcastle y a otras enfer- 
medades (Giambrone et al., 1977). Si consideramos que hay otros patógenos aviares circulando en la comunidad, la disminución de la capacidad inmunitaria crearía condiciones de concomitancia que podrían afectar la capacidad de las aves para controlar los desafíos de campo y esto se traduciría en un aumento de la mortalidad.

La presencia de poblaciones de gallinas en más de 20 comunidades de la RBM (Consejo Nacional de Áreas Protegidas y Wildlife Conservation Society, 2013) junto con la existencia de humedales que albergan una gran diversidad de aves silvestres, genera las condiciones suficientes para que ocurran brotes de enfermedad (Gilchrist, 2005). El hecho de que la tercera parte de las gallinas estudiadas en la AEC porten concomitantemente anticuerpos contra el VIA, el VENC y el VEG es un hallazgo interesante y es un indicio de la diversidad de los patógenos aviares que podrían encontrarse al desarrollar un estudio epidemiológico más profundo.

La no detección de anticuerpos contra Mycoplasma gallisepticum y Salmonella pullorum es un hallazgo interesante ya que se trata de enfermedades comunes en Centro América y Suramérica (Mitchell, 1984). En una investigación en curso en el departamento de Jalapa, situado al sur-oriente de Guatemala, se han detectado anticuerpos contra Mycoplasma gallisepticum y $M$. sinoviae en gallinas de patio (Aquino-Sagastume et al., in prep).

El hecho de que los patógenos se presenten de manera concomitante, predispone a las gallinas de la AEC a sucumbir a la infección durante la época de escasez de recursos alimenticios en el ambiente. De hecho, los comunitarios que fueron abordados en el presente estudio, manifestaron que al final de la época seca, el llamado "accidente" causa la muerte de la mayoría de las gallinas por lo que se ven obligados a traer gallinas de otros sectores de la aldea o de otras aldeas.
Finalmente, a pesar de que se trata de enfermedades comunes y bien estudiadas, la información epidemiológica de poblaciones de gallinas de patio de comunidades rurales es sumamente escasa. Esto significa que estas enfermedades son, en cierta medida, desatendidas. Esto tiene serias implicaciones que podrían comprometer la seguridad alimentaria de un país como Guatemala, donde el $51 \%$ de la población es rural (Instituto Nacional de Estadística, 2013) y el 59.3\% es pobre (Instituto Nacional de Estadística, 2015). La atención a estas enfermedades es responsabilidad del Estado, en su calidad de ente promotor de la salud.

\section{Conclusiones}

Dado que no se acostumbra vacunar a las aves de patio en la AEC, el hallazgo de anticuerpos contra el VIA, el VENC y el VEG es indicio de la circulación de estos agentes etiológicos en la población de gallinas de la AEC.

A pesar de que el muestreo del presente estudio fue de tipo exploratorio, se detectaron anticuerpos contra el VIA, contra el VENC y contra el VEG en el $46 \%, 31 \%$ y $95 \%$ de las aves muestreadas, respectivamente.

El $31 \%$ de las gallinas muestreadas, portaba anticuerpos contra tres patógenos (VIA, VENC y VEG) y el $15 \%$ contra dos patógenos (VENC y $V E G)$.

Los anticuerpos contra el VENC se detectaron únicamente en el muestreo del mes de septiembre.

Aunque se trata de bacterias comunes en aves domésticas, no se encontraron indicios de la circulación de MG y de SP en las gallinas de patio de la AEC.

La cercanía de la AEC con ciudades pobladas, humedales y áreas naturales protegidas representa un riesgo para la diseminación y mantenimiento de los patógenos aviares encontrados, amenazando la salud pública, la industria 
avícola y la conservación de la diversidad de aves del país.

Dada la cercanía de la AEC con ciudades pobladas, humedales y áreas naturales protegidas turísticas, se considera que la población flotante de gallinas de patio de esa comunidad representa una potencial amenaza para la avicultura artesanal, la avicultura tecnificada, las aves silvestres y la población humana.

\section{Agradecimientos}

Se agradece al señor Marcial Córdova, de Wildlife Conservation Society por el apoyo logístico en el muestreo en la AEC.

\section{Referencias}

Aini, I. (2013). Diseases in rural family chickens in south-east Asia. In Food \& Agriculture Organization, The scope and effect of family poultry research and development. First INFPD/FAO Electronic Conference on Family Poultry (pp. 37-41). Rome: FAO.

Ajuyah, A. O. (2013). Family poultry management systems in Africa. In Food \& Agriculture Organization, The scope and effect of family poultry research and development. First INFPD/FAO Electronic Conference on Family Poultry (pp. 45-50). Rome: FAO.

Alexander, D. J. (1995). The epidemiology and control of avian influenza and Newcastle disease. Journal of comparative pathology, 112(2), 105-126.

Alexander, D. J. (2000). Newcastle disease and other avian paramyxoviruses. Revue Scientifique et Technique-Office International des Epizooties, 19(2), 443-455.

Beldomenico, P. M., y Uhart, M. M. (2008). Ecoepidemiología de los virus de influenza aviar. FAVE Sección Ciencias Veterinarias, $7(1 / 2), 23-40$.

Camacho-Escobar, M., Lira-Torres, I., Ramírez-Cancino, L., López-Pozos, R. y
Arcos-García, J. (2006). La avicultura de patio en la costa de Oaxaca, México. Ciencia y Mar, 10(28), 3-11.

Cavanagh, D. (2007). Coronavirus avian infectious bronchitis virus. Veterinary research, 38(2), 281-297.

Cavanagh, D. y Gelb, J. (2003). Infectious bronchitis. En Saif, Y. M. (Ed.), Diseases of poultry, (pp. 117-134). New Jersey: Blackwell Publishing.

Christensen, A. F. (2000). The fifteenth-and twentieth-century colonization of the Basin of Mexico by the Great-tailed Grackle (Quiscalus mexicanus). Global Ecology and Biogeography, 9(5), 415-420.

Consejo Nacional de Áreas Protegidas y Wildlife Conservation Society. (2013). Estimación indirecta de la tasa de crecimiento y tamaño actual de la población y encuesta socioeconómica de la RBM. San Benito, Petén: CONAP-WCS.

De Sahagún, B. (1830). Historia general de las cosas de Nueva España: que en doce libros y dos volúmenes escribió el RP Fr. Bernardino de Sahagún. Dala á luz con notas y suplementos Carlos Maria de Bustamante,... . C. M. de Bustamante (Ed.). México: Imprenta del ciudadano Alejandro Valdés.

Eisermann, K., y Avendaño, C. (2006). Evaluation of waterbird populations and their conservation in Guatemala. Guatemala: Waterbirds Conservation for the Americas.

Gage, Tomás. (2000). Los viajes de Tomás Gage a la Nueva España. Parte tercera: Guatemala. Guatemala: Artemis-Edinter.

Gaidet, N., Cattoli, G., Hammoumi, S., Newman, S. H., Hagemeijer, W., Takekawa, J. Y., ... y Monne, I. (2008). Evidence of infection by H5N2 highly pathogenic avian influenza viruses in healthy wild waterfowl. PLoSPathog, 4(8), e1000127. 
Ghidinelli, A. (1986). El sistema de ideas sobre la enfermedad en Mesoamérica. Revista Médica Hondureña, 52(4), 237-248.

Giambrone, J. J., Eidson, C. S., y Kleven, S. H. (1977). Effect of infectious bursal disease on the response of chickens to Mycoplasma synoviae, Newcastle disease virus, and infectious bronchitis virus. American journal of veterinary research, 38(2), 251-253.

Gilchrist, P. (2005). Involvement of free-flying wild birds in the spread of the viruses of avian influenza, Newcastle disease and infectious bursal disease from poultry products to commercial poultry. World's poultry science journal, 61(02), 198-214.

Glass, J. W., Fedynich, A. M., Small, M. F., y Benn, S. J. (2002). Helminth community structure in an expanding white-winged dove (Zenaida asiatica asiatica) population. Journal of Wildlife Diseases, 38(1), 68-74.

González-Reiche, A. S., y Perez, D. R. (2012). Where do avian influenza viruses meet in the Americas? Avian diseases, 56(4s1), 1025-1033.

Gottdenker, N. L., Walsh, T., Vargas, H., Merkel, J., Jiménez, G. U., Miller, R. E., ... y Parker, P. G. (2005). Assessing the risks of introduced chickens and their pathogens to native birds in the Galápagos Archipelago. Biological Conservation, 126(3), 429-439.

Guèye, E. F. (2002). Employment and income generation through family poultry in low-income food-deficit countries. World's Poultry Science Journal, 58(04), 541-557.

Hawkins, M. G., Crossley, B. M., Osofsky, A., Webby, R. J., Lee, C. W., Suarez, D. L., y Hietala, S. K. (2006). Avian influenza A virus subtype $\mathrm{H} 5 \mathrm{~N} 2$ in a red-lored Amazon parrot. Journal of the American Veterinary Medical Association, 228(2), 236-241.
Instituto Nacional de Estadística (Guatemala). (2013). Caracterización estadística República de Guatemala 2012. Guatemala: Instituto Nacional de Estadística.

. 2015. República de Guatemala: Encuesta Nacional de Condiciones de Vida 2014. Guatemala: Instituto Nacional de Estadística.

Kitalyi, A. J. (2013). Family poultry management systems in Africa. In Food \& Agriculture Organization, The scope and effect of family poultry research and development. First INFPD/FAO Electronic Conference on Family Poultry (pp. 45-50). Rome: FAO.

Kumtakar, V. A. y Kumtakar, P. (2013). Rural family poultry scenario in tribal areas of central Madhya Pradesh, India - a socio-economic analysis. In Food \& Agriculture Organization, The scope and effect of family poultry research and development. First INFPD/FAO Electronic Conference on Family Poultry (pp. 135-142). Rome: FAO.

MacGregor-Fors, I., Vázquez, L., Vega-Rivera, J. H., y Schondube, J. E. (2009). Non-exotic invasion of Great-tailed Grackles Quiscalus mexicanus in a tropical dry forest reserve. Ardea, 97(3), 367-369.

Mallia, J. G. (1999). Observations on family poultry units in parts of Central America and sustainable development opportunities. Livestock Research for Rural Development, 11(3).

(2013). Observations on family poultry units in parts of Central America and sustainable development opportunities. In Food \& Agriculture Organization, The scope and effect of family poultry research and development. First INFPD/FAO Electronic Conference on Family Poultry (pp. 179-190). Rome: FAO. 
Mérida, S. A., Guerra-Centeno, D. S., Bailey, L., Rohn, K., Kösters, S., \& Kreienbrock, L. (2016). Participatory epidemiology at the neotropics: study of diseases of backyard livestock and description of hunting patterns in Uaxactún, Maya Reserve Biosphere, Guatemala. BMC research notes, 9(1), 1-12. DOI 10.1186/ s13104-016-2009-3

Mitchell, D. F. (1984). Incidence and control of poultry diseases in Central and South America. Preventive Veterinary Medicine, 2(1), 269-276.

Moreki, J. C. (2010). Village poultry production in Serowe-Palapye sub-district of Botswana. Livestock Research for Rural Development, 22(3), 46.

Office International Des Epizooties. (2015). Manual of Diagnostic Tests and Vaccines for Terrestrial Animals: Mammals, Birds and Bees. Paris: Office International Des Epizooties.

Ogata, T., Yamazaki, Y., Okabe, N., Nakamura, Y., Tashiro, M., Nagata, N., ... y Izumi, Y. (2008). Human H5N2 avian influenza infection in Japan and the factors associated with high H5N2-neutralizing antibody titer. Journal of epidemiology, 18(4), 160-166.

Okamatsu, M., Saito, T., Yamamoto, Y., Mase, M., Tsuduku, S., Nakamura, K., ... y Yamaguchi, S. (2007). Low pathogenicity H5N2 avian influenza outbreak in Japan during the 2005-2006. Veterinary microbiology, 124(1), 35-46.

Olsen, B., Munster, V. J., Wallensten, A., Waldenström, J., Osterhaus, A. D., y Fouchier, R. A. (2006). Global patterns of influenza $A$ virus in wild birds. Science, 312(5772), 384-388.

Pillai, S. P. S., Suarez, D. L., Pantin-Jackwood, M., y Lee, C. W. (2008). Pathogenicity and transmission studies of H5N2 parrot avian influenza virus of Mexican lineage in different poultry species. Veterinary microbiology, 129(1), 48-57.

Ramey, A. M., Poulson, R. L., González-Reiche, A. S., Wilcox, B. R., Walther, P., Link, P., ... y Perez, D. R. (2014). Evidence for seasonal patterns in the relative abundance of avian influenza virus subtypes in bluewinged teal (Anas discors). Journal of wildlife diseases, 50(4), 916-922.

Ramlah, A. H. (2013). Production aspects of village chicken in the south-east Asian region. In Food \& Agriculture Organization, The scope and effect of family poultry research and development. First INFPD/ FAO Electronic Conference on Family Poultry (pp. 61-66). Rome: FAO.

Schelling, E., Thur, B., Griot, C., y Audige, L. (1999). Epidemiological study of Newcastle disease in backyard poultry and wild bird populations in Switzerland. Avian Pathology, 28(3), 263-272.

Senne, D. A. (2007). Avian influenza in North and South America, 2002-2005. Avian diseases, 51(s1), 167-173.

Sharma, J. M., Kim, I. J., Rautenschlein, S., y Yeh, H. Y. (2000). Infectious bursal disease virus of chickens: pathogenesis and immunosuppression. Developmental y Comparative Immunology, 24(2), 223-235.

Sigüenza de Micheo, R. (2007). Informe de conteos de Anátidas en Guatemala: Temporada 2006-2007. Universidad de San Carlos de Guatemala, editor (2007) Fundación Defensores de la Naturaleza EdB. Guatemala: Ducks Unlimited.

Small, M. F., Schaefer, C. L., Baccus, J. T., y Roberson, J. A. (2005). Breeding ecology of white-winged doves in a recently colonized urban environment. The Wilson Bulletin, 117(2), 172-176. 
Suárez, D. L., Spackman, E., y Senne, D. A. (2003). Update on molecular epidemiology of $\mathrm{H1}, \mathrm{H} 5$, and $\mathrm{H} 7$ influenza virus infections in poultry in North America. Avian diseases, 47(s3), 888-897.

Vandegrift, K. J., Sokolow, S. H., Daszak, P., y Kilpatrick, A. M. (2010). Ecology of avian influenza viruses in a changing world. Annals of the New York Academy of Sciences, 1195(1), 113-128.

Webster, R. G., Hulse-Post, D. J., SturmRamírez, K. M., Guan, Y., Peiris, M., Smith, G., y Chen, H. (2007). Changing epidemiology and ecology of highly pathogenic avian $\mathrm{H} 5 \mathrm{~N} 1$ influenza viruses. Avian diseases, 51(s1), 269-272.
Wehtje, W. (2003). The range expansion of the great-tailed grackle (Quiscalus mexicanus Gmelin) in North America since 1880. Journal of Biogeography, 30(10), 1593-1607.

Wilson, R. T., Traore, A., Kuit, H. G., y Slingerland, M. (1987). Livestock production in central Mali: Reproduction, growth and mortality of domestic fowl under traditional management. Tropical animal health and production, 19(4), 229-236.

Wunderwald, C., \& Hoop, R. K. (2002). Serological monitoring of 40 Swiss fancy breed poultry flocks. Avian Pathology, $31(2), 157-162$. 